\title{
Insulin use at the top of the world
}

\author{
Author: Jatinder Mokta
}

\begin{abstract}
Aims
The diabetes pandemic knows no geographical boundaries. Along with modernisation, diabetes has reached the remote Himalayan areas of Lahaul-Spiti and Kinnaur, in the Indian state of Himachal Pradesh located in the upper reaches of the Western Himalayas. Inhabited predominantly by the tribal population, these districts are located at an altitude of 8,000-16,000 feet above sea level. The unique geographic conditions and far and scarce medical service impose great challenges for the management of diabetes in this part of the world.
\end{abstract}

\section{Methods}

Ever since the discovery of insulin in 1921, a lot is talked about the synthesis of newer insulin. However, little is talked about its storage in the extreme of temperature, like that found in the Himalayas, and this improvised method of insulin storage may be of great value for those diabetic patients living at top of the world.

\section{Results}

Three patients from tribal areas living at an 'altitude' of 9,500, 12,000 and 14,500 feet at a distance of 250 and $550 \mathrm{~km}$ from the state capital were prescribed insulin for uncontrolled blood sugar. The unique geographic condition of these areas, and peculiar social habits and dietary patterns of the inhabitants, imposes unique challenges for the use of insulin in this part of the world. Besides having the danger of hypoglycaemia, the biggest challenge remains how to store insulin in the winter when outside temperature dips to minus $30^{\circ} \mathrm{C}$, mostly during midnight, and the inside temperature of the living room goes up to between $40-70^{\circ} \mathrm{C}$ due to constant burning of 'Bukhari' made up of iron. Difficulty in access and storage of insulin creates a need for crafting a locally relevant, improvised solution. In winter, people of these areas wear warm clothes made up of sheep and yak wool to protect them from severe cold. One such unique cloth people wear in the winter is an abdominal binder, which measures 2-3 feet in width and 5-15 feet in length. Seeing a woman wearing the traditional attire in a hospital, an innovative idea of insulin storage that was 'locally' relevant and easily acceptable came to my mind. It was planned to store insulin in multiple layers of

Author: Indira Gandhi Medical College, Shimla, Himachal Pradesh India abdominal binder, which prevents it from freezing in winter. This was discussed with patients on their follow-up visit. They were advised to wrap the insulin vials and/ or pens in 'multiple layers' in the abdominal binder (where the temperature recorded was between $5-10^{\circ} \mathrm{C}$ ). The success of this practice was evident from the normal $\mathrm{HbA} 1 \mathrm{c}$ values, and the smiles on their faces when they visit the state capital for routine medical consultation.

\section{Conclusion}

Normally we think of living with diabetes at normal altitude, not for those living in the extreme conditions of the world, like those living in the Himalayas. Improving the technology to synthesise an insulin that is stable at sub-zero temperature, like that found in the Himalayas, will be a step forward in a better diabetes care to individuals living in such harsh environments.

\section{Conflict of interest statement}

None declared. 